\title{
A construção do conhecimento fonológico na aquisição da linguagem
}

\author{
Construction of phonological knowledge in language \\ acquisition
}

\section{Carmen Lúcia Barreto Matzenauer Universidade Católica de Pelotas Ana Ruth Moresco Miranda Universidade Federal de Pelotas}

\section{Resumo}

Este artigo visa precipuamente a apresentar uma discussão sobre o fenômeno da aquisição da fonologia. Apresenta três grandes focos: (a) um exame do processo da aquisição da fonologia por crianças falantes nativas do português do Brasil (PB), com a retomada de estudos desenvolvidos no país; (b) a caracterização e a exemplificação do fenômeno da aquisição da linguagem com base em unidades da fonologia da língua: sílaba, segmento e traços; e (c) a explicitação desse processo de desenvolvimento linguístico à luz de modelos teóricos da área da fonologia.

\section{Palavras-chave}

Aquisição da fonologia, Fonologia do português, Teoria fonológica.

\section{Abstract}

This paper aims to present a discussion about the phenomenon of the acquisition of phonology. It has three major foci: (a) to examine the process of the acquisition of phonology by children 
who are native speakers of Brazilian Portuguese (BP), with a review of studies that have been developed in Brazil; (b) to characterize and exemplify the phenomenon of language acquisition based on the following units of language phonology: syllable, segment and features; and (c) to clarify this process of language development in the light of theoretical models in the area of phonology.

\section{Keywords}

Acquisition of phonology, Phonology of Portuguese, Phonological theory. 


\section{Considerações Iniciais}

$1 \begin{gathered}\text { criança oferece a única oportunidade que nós temos para observar a } \\ \text { linguagem em seu estado nascente. Esta citação de Karl Bühler é a } \\ \text { primeira frase que se lêe em Child Language, Aphasia and Phonological }\end{gathered}$ Universals, obra seminal de Jakobson escrita em 1941, traduzida para o inglês em 1968 e referência obrigatória para os estudos sobre aquisição da fonologia ainda hoje. Tal afirmação aponta para os caminhos que foram trilhados posteriormente pelos estudos sobre o desenvolvimento da linguagem, sobretudo após o advento do Gerativismo que, ao colocar a aquisição como um problema central para os estudos linguísticos, estimulou o desenvolvimento de pesquisas cujo foco incide em questões pertinentes à teoria linguística.

O estudo de Jakobson (1941/1968) está identificado com a ideia de uma teoria linguística universal, à medida que é capaz de formular restriçōes à fonologia das primeiras palavras produzidas pelas crianças e propor uma ordem invariável para o surgimento das oposiçôes fonológicas, feitos realizados a partir da discussão de dados de aquisição e de perda da linguagem, bem como de tipologias de línguas do mundo. Para responder à pergunta sobre a natureza da relação inicial entre consoante e vogal, o autor reflete sobre as relaçôes sintagmáticas, isto é, as sequências estruturais em sua relação contextual - sílaba; e as paradigmáticas, referentes ao inventário de consoantes e vogais nas suas relaçōes de substituição.

De acordo com a ordem de aquisição proposta pelo autor, a primeira estrutura silábica adquirida, CV, será preenchida por uma plosiva labial e uma vogal aberta, podendo ser duplicada. A primeira oposição consonantal observada deverá ser entre plosiva e labial, 'papa'-'mama'; e a segunda entre labial e dental, 'papa'- 'tata' e 'mama'-'nana'. A primeira oposição vocálica se dará entre vogal baixa e alta, 'papa'-'pipi'; e a segunda entre 'papa'-'pipi'-'pupu' ou 'papa'-'pipi''pepe'. Essas prediçôes, que constrangem a forma fonológica das primeiras palavras, baseiam-se em leis de solidariedade irreversível, as quais têm caráter implicacional e orientam a aquisição fonológica. 
Um exemplo de funcionamento da lei de solidariedade irreversível pode ser dado a partir de uma observação referente ao ponto de articulação de consoantes, em se considerando as línguas do mundo. Se em todas as línguas há consoantes anteriores, sem que as posteriores nela sejam encontradas, predições podem ser feitas em relação às tipologias, à aquisição e à afasia: i) para que uma língua tenha consoantes posteriores, terá de ter também anteriores; ii) para que as crianças produzam posteriores, terão de ser capazes de produzir as anteriores; e iii) para os casos de perda da capacidade fonológica, posteriores serão afetadas antes das anteriores. Com essa proposta, Jakobson filia-se às abordagens que se enquadram em uma perspectiva condizente com aquela das pesquisas dedutivas voltadas à teoria, ${ }^{1}$ as quais visam, para além de boas descrições dos fenômenos e dos padrões observados na linguagem da criança, obter adequação explanatória, ao assumirem a discussão referente ao problema lógico da aquisição e ao conhecimento linguístico, conforme postos por Chomsky $(1965,2006)$.

A formulação chomskiana para o Problema de Platão (Como pode o ser humano saber tanto a partir de tão poucas evidências?), ao ser caracterizada como Problema Lógico da Aquisiçāo, coloca a aquisição da linguagem pela criança como questão central para o desenvolvimento de uma teoria linguística e propicia, na década de 1960, um forte incremento aos estudos da Psicolinguística, que surge como campo de estudo interdisciplinar. A epistemologia inatista, de base racionalista, em suas versōes forte e fraca - maturacionismo e construtivismo ${ }^{2}$ - pode ser considerada hegemônica nos estudos sobre aquisição da linguagem, antes dominados pela perspectiva empirista.

Sobre os efeitos das diferentes posições epistemológicas, Macken (1995, p. 672) argumenta ser este um empecilho ao progresso dos estudos, já que a polarização entre empiristas e racionalistas ${ }^{3}$ muitas vezes tira o foco de dois aspectos que, para a autora, são centrais aos estudos de aquisição fonológica, a saber: i) a fonologia compreende a fonética - objetos, restriçôes e princípios da fonologia não são determinados por seu conteúdo fonético e tampouco explicados de forma completa pela teoria fonética; e ii) alguns aspectos da língua são aprendidos, outros, inatos. Segundo Macken (op. cit.), a questão central deve ser aquela referente ao problema lógico da aquisição - como aprendemos a partir de input incompletos e contraditórios - e a resposta está, em parte, nas estruturas a priori que determinam a velocidade de aquisiçāo, as restriç̧ōes sobre variação e a independência de fatores limitantes, como a inteligência. 
Kiparsky e Menn (1979), Slobin (1980), Macken (1992, 1995), Karmiloff-Smith (1992), entre outros, compartilham a ideia de que, no processo de desenvolvimento da linguagem, um mecanismo de aquisição central controla a integração de princípios gerais e padrões de línguas particulares, permitindo e, ao mesmo tempo, restringindo a formação de hipóteses da criança a respeito da estrutura e do funcionamento de sua língua. Nesse jogo, torna-se possível à criança a descoberta dos padrōes fonológicos de sua língua materna em um exercício de criatividade regida por regras. Conceber desse modo o processo de aquisição da fonologia é garantia de que o desenvolvimento linguístico, a variação e as características individuais (ritmos e estratégias escolhidos) podem ser conciliados com a ideia de estruturas universais e padrões gerais de aquisição.

Considera-se que a pertinência do apoio de estudos sobre aquisição da linguagem em teorias fonológicas pode ter uma de suas bases na assunção da hipótese da continuidade entre a fonologia da criança e a fonologia do adulto a continuidade supõe que os sistemas linguísticos da criança e do adulto variam de forma limitada. Estudos com base nos modelos não-lineares (Fonologia Autossegmental, Métrica e Prosódica), assim como na Teoria da Otimidade (Optimality Theory-OT), assumem a continuidade ao defender que a fonologia do adulto e a da criança têm a mesma substância.

Apesar da complexidade do tema, das interfaces que o integram e das questôes que ainda se encontram em aberto, em muito o conhecimento sobre o processo de aquisição da fonologia avançou no Brasil desde os anos 80, incluindo um consistente corpo teórico, explicitado em diferentes análises apresentadas por integrantes dos núcleos de estudo sobre o assunto que existem no país. Nas investigaçoes sobre aquisição fonológica, merece destaque a relação estabelecida com modelos teóricos da ciência linguística, o que é feito na busca do entendimento da forma como o processo de aquisição se desenvolve e da natureza que o caracteriza, ou seja, da forma como se constrói o conhecimento fonológico.

Este artigo ${ }^{4}$ apresenta uma visão referente aos estudos produzidos no Brasil sobre o fenômeno da aquisição da fonologia. Tendo como foco o processo de desenvolvimento linguístico considerado típico (normal $)^{5}$ de crianças falantes nativas do português brasileiro (PB), busca tematizar a aquisição com base em unidades da fonologia da língua - sílaba, segmento e traços -, utilizando o suporte de modelos teóricos da área da fonologia. 


\section{Base empírica}

Os dados longitudinais apresentados foram coletados desde as primeiras palavras de L, nascida em $1^{\circ}$ de março de 2002 . Os registros foram feitos por meio de anotações, gravações em fita cassete (depois digitalizadas) e em vídeo. As coletas, a partir das primeiras 50 palavras, aos 1:09,27, foram realizadas com intervalos iguais ou menores do que 30 dias, sempre no ambiente familiar da criança. Para este estudo, foram selecionadas três entrevistas, que servem de subsídio para a análise de aspectos concernentes à aquisição segmental; são utilizados especificamente os dados de três entrevistas, com diferença de meses - idades: 1:09,27; 2:00,01 e 2:07,29 -, capazes de representar fases no desenvolvimento fonológico da menina. Sendo o foco do presente estudo o processo de aquisição do sistema consonantal da língua-alvo, após os exemplos caracterizadores de cada fase de desenvolvimento, apresenta-se o sistema de consoantes que integra a gramática fonológica de L naquele momento.

\subsection{Exemplos de dados de $\mathrm{L}$ - Fase 1 deste estudo - idade: $1: 09,27$}

\begin{tabular}{|c|c|c|c|}
\hline acabou & [a'bo] & macaco & [ka'kaku] \\
\hline colo & ['ko] & nanar & [na'na] \\
\hline doce & {$\left[\mathrm{do} \int \mathrm{u}\right]$} & sai & ['taj] \\
\hline elefante & ['tete] & sapo & ['papu] \\
\hline espinho & ['piñu] - [pi'piñu] & sorvete & ['det $\left.\int \mathrm{i}\right]$ \\
\hline fósforo & ['fofu] & suco & ['kuhu] $\sim$ ['kuku] \\
\hline Heitor & {$\left[{ }^{\prime}\right.$ to $] \sim[$ to'to $]$} & urso & {$[$ 'tusu $] \sim\left[\right.$ tu $\left.\int \mathrm{u}\right]$} \\
\hline lagartixa & ['tisi] & Vera & {$\left[{ }^{\mathrm{c}} \mathrm{z} \varepsilon\right] \sim[\mathrm{c} \mathrm{d} \varepsilon]$} \\
\hline
\end{tabular}

Na Fase 1, o sistema consonantal de L é o seguinte:

Sistema consonantal de L $(1: 09,27)^{6}$

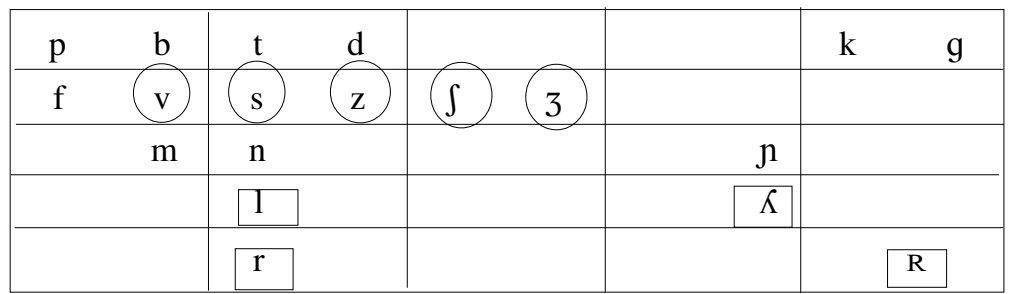


Nessa fase, duas classes de consoantes da língua já se encontram completas: a classe das consoantes plosivas e a das nasais, em consonância com o que se deveria esperar, de acordo com os estudos de Jakobson (1941/1968). Entre as fricativas, apenas a labial desvozeada /f/ pode ser considerada adquirida, já que as outras consoantes dessa classe têm emprego variável. Não há qualquer líquida integrando a fonologia de L nessa fase da aquisição fonológica.

\subsection{Exemplos de dados de L - Fase 2 deste estudo - idade: 2:00,01}

\begin{tabular}{|c|c|c|c|}
\hline balāo & [bâããw] & falei & [fäjej] \\
\hline bolacha & [bu'ate] & Juju (Juliana) & [zu'zu] \\
\hline brincar & [bi'ka] & Mara & ['maje] \\
\hline café & {$\left[\mathrm{fa}^{\prime} \mathrm{f} \varepsilon\right]$} & molhou & [mu’jo] \\
\hline doce & {$\left[\right.$ dot $\left.\int \mathrm{i}\right]$} & Neve (Branca de) & ['vevi] \\
\hline escovar dentes & [vu'va 'det $\int \mathrm{i}$ ] & Rafa & ['vafe] \\
\hline u só & ['ew 'so] & show & ['Sow] \\
\hline
\end{tabular}

Na Fase 2, este é o sistema consonantal de L:

Sistema consonantal de L $(2: 00,01)$

\begin{tabular}{|c|c|c|c|c|c|c|}
\hline $\mathrm{p}$ & $\mathrm{b}$ & $\mathrm{t}$ & $\mathrm{d}$ & & & $\mathrm{k}$ \\
\hline $\mathrm{f}$ & $\mathrm{v}$ & s) & $z$ & 3 & & \\
\hline & $\mathrm{m}$ & & $\mathrm{n}$ & & $\mathrm{n}$ & \\
\hline & & & 11 & & $\Lambda$ & \\
\hline & & & $\mathrm{r}$ & & & $\mathrm{R}$ \\
\hline
\end{tabular}

A fonologia de L, nessa Fase 2, passados quase três meses da fase anterior, mostrou avanço apenas na aquisição da fricativa vozeada /v/. 


\subsection{Exemplos de dados de L - Fase 3 deste estudo - idade: $2: 07,29$}

\begin{tabular}{|c|c|c|c|}
\hline barraca & [ba’lake] & garrafa de coca & [ga'lafe de 'koke] \\
\hline bolacha & $\left[\right.$ bo'la $\left.\int e\right]$ - [bo'ja $\left.\int e\right]$ & jogando bola & [zo'g gên du 'boje] \\
\hline cachorro & [ka’’oju] & lavou & [a’vo] \\
\hline cerveja & [se'veze] & não cabem & [nãw̃ ‘kajbẽj)] \\
\hline controle & [kơn'toje] & não me logra & [nãw̃ mi’oge] \\
\hline doce de fruta & ['dosi d fi 'fute] & primeiro & [pe'meju] \\
\hline (es)tá sujo & [ta’suzu] & sorvete & [so'vet $\left.\int \mathrm{i}\right]$ \\
\hline u quero ver o peixe & [ew ‘kzju 've u’ pesi] & sou grande & {$\left[\right.$ so'g $\left.\tilde{e}^{\mathrm{n}} \mathrm{d} 3 \mathrm{i}\right]$} \\
\hline
\end{tabular}

$\mathrm{Na}$ Fase 3, o sistema consonantal de L inclui estas consoantes:

Sistema consonantal de L $(2: 07,29)$

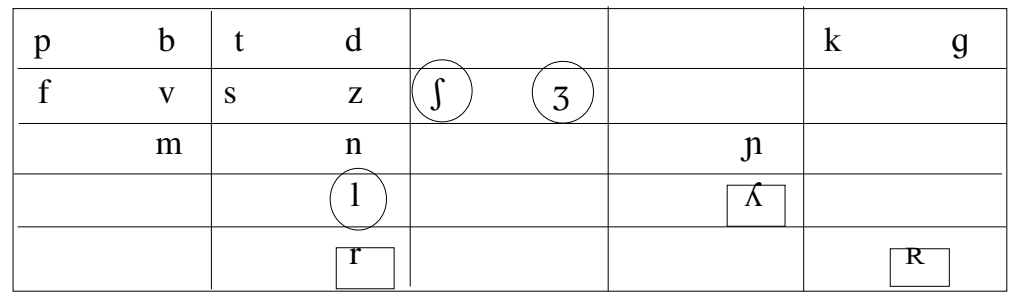

Na Fase 3 aqui referida, passados sete meses da anterior, a fonologia de $\mathrm{L}$ passou a incluir as fricativas coronais anteriores /s/ e /z/, além de mostrar, sem estabilidade ainda, a emergência do emprego da primeira consoante líquida: a lateral anterior $/ 1 /$.

Os dados aqui exemplificados serão retomados nas seções subsequentes, na discussão do processo de aquisição das unidades da fonologia da língua.

\section{Os segmentos e os traços na aquisição fonológica do PB}

A construção do inventário de consoantes e de vogais do sistema-alvo, durante o processo de aquisição da linguagem, implica a discussão sobre segmentos e sobre os traços que constituem sua estrutura interna. Considerando esses dois níveis de análise, já foram propostos diferentes modelos teóricos que os assumem como seu foco e, em decorrência, houve estudos sobre o processo de aquisição fonológica que os elegeram como fundamento. 


\subsection{Sobre a aquisição de segmentos}

A aquisição dos segmentos de uma língua é aferida pela construção do inventário de consoantes e vogais pelas crianças - o foco do presente estudo está na construção do inventário consonantal por crianças falantes nativas de PB.

Ao tratar-se de segmentos, destaca-se que constituem a unidade que, em um primeiro momento, parece ser capaz de evidenciar com clareza a especificidade $\mathrm{da}(s)$ gramática(s) das crianças em comparação à do falante adulto - a qualquer falante / ouvinte do PB é facilmente perceptível o apagamento de segmentos (como na forma [ba'ate] para barata, por exemplo) ou o emprego de um segmento por outro (como na forma [ba'late] para barata, por exemplo). Vinculada a essa realidade, bem como ao entendimento advindo da Teoria Gerativa Clássica de que no processamento da linguagem a criança realiza operaçóes mentais, surgiu a proposta de Stampe (1973) e Donegan e Stampe (1979) - a Teoria da Fonologia Natural -, que, denominando tais operações de processos fonológicos, atribuiu-lhes papel central na aquisição. À luz da Teoria da Fonologia Natural, a aquisição era vista como a supressão de processos naturais, inatos, universais, que não estivessem presentes na língua-alvo, por exemplo, redução de encontro consonantal, apagamento de líquida final, plosivização, anteriorização, posteriorização, substituição de líquida.

Nos anos 80, com o suporte da Teoria da Fonologia Natural, numerosos estudos foram dedicados à aquisição da fonologia, especialmente do inglês (Estados Unidos e Inglaterra) e do português (Brasil), versando tanto sobre o desenvolvimento fonológico considerado normal, como sobre aquele identificado como atípico. Essa é uma base teórica ainda hoje muito utilizada no campo da fonoaudiologia, já que propicia descrição simples de sistemas fonológicos, bem como fácil comparação da fonologia da criança com a do adulto. No Brasil, de forma particular no Rio Grande do Sul, muitos foram os estudos, tanto sobre desenvolvimento fonológico normal como com desvios, que contribuíram decisivamente para a descrição do processo de aquisição da fonologia do PB com fundamento na Teoria da Fonologia Natural; citam-se apenas alguns: Lamprecht (1986, 1990); Yavas (1988); Ramos (1991), Rosa (1992); Varella (1993); Ilha (1993); entre outros. ${ }^{7}$

Para exemplificar a visão que essa abordagem empresta à aquisição fonológica, na seção seguinte é apresentada uma breve discussão dos dados da menina L, referidos na Seção 2, com os subsídios da Fonologia Natural. 


\subsection{Abordagem dos dados de L com base em segmentos}

À luz dos pressupostos da Teoria da Fonologia Natural, a gramática fonológica de L, na denominada Fase 1, apresenta diferentes processos que afetam o inventário de segmentos consonantais, além daqueles que Stampe categorizava como processos de estrutura silábica. Exemplos de processos segmentais que integram a fonologia de L nesse estágio de desenvolvimento são: sai ['taj]; sorvete

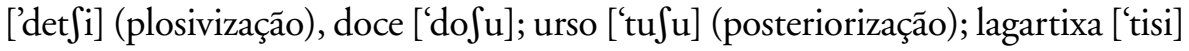
(anteriorização).

Os dados de L mostram também muitas ocorrências de reduplicações e de assimilações consonantais, conforme ilustram estes exemplos: elefante ['tete]; Heitor [to'to]; sapo ['papu]; suco ['kuku]. Os processos de apagamento de segmentos são captados pela teoria como processos de estrutura silábica.

$\mathrm{Na}$ Fase 2, a única consoante cujo status fonológico mostra alteração é a fricativa vozeada $/ \mathrm{v} /$, que passa a mostrar estabilidade. Continuam as ocorrências dos processos segmentais identificados como plosivização, posteriorização (esses com menor frequência), anteriorização e começa a manifestar-se a semivocalização de líquida, além dos processos de estrutura silábica. Aumenta, nesse estágio, a ocorrência de assimilaçōes consonantais.

A seguir, na Fase 3, as fricativas coronais anteriores /s/ e /z/ têm o status fonológico estabilizado, bem como a líquida lateral anterior passa a emergir, alternando-se com o glide coronal e o zero fonético (este exclusivamente no início de palavra). No nível segmental, são suprimidos os processos de plosivização e posteriorização, mantendo-se os processos de anteriorização e semivocalização de líquida, além daqueles de estrutura silábica. Também permanece a ocorrência de assimilações consonantais.

Em um desenvolvimento contínuo, a menina $\mathrm{L}$ vai construindo o inventário de consoantes, suprimindo progressivamente os processos fonológicos, que contribuíam para tornar sua gramática diferente da língua-alvo. ${ }^{8}$

Apesar da consistência e da simples operacionalidade exigida pela análise de dados infantis com base em processos fonológicos, a Teoria da Fonologia Natural oferece alguns entraves à busca de respostas cruciais sobre o funcionamento da fonologia da criança durante o seu desenvolvimento linguístico. Com base nos dados de L aqui apresentados, algumas questōes podem ser postas: i) o pressuposto de que a criança aplica processos a formas de input implica o entendimento de que, desde o início do desenvolvimento linguístico, a 
representação fonológica de que ela dispõe é igual à do adulto? ii) Por que processos diferentes são aplicados a diferentes classes de segmentos, isto é, por que, por exemplo, fricativas plosivizam e líquidas semivocalizam? iii) Por que os processos de anteriorização e de posteriorização têm como alvo primordialmente as fricativas coronais?

Tais inquietações, vinculadas à natureza do processo de aquisição fonológica, levaram a pesquisas com base em uma unidade menor do que o segmento - os traços -, responsáveis pelo funcionamento da fonologia das línguas naturais.

\subsection{Sobre a aquisição de traços}

Os estudos em fonologia são unânimes em reconhecer a relevância da unidade traço na teoria linguística. Clements e Hume (1995) iniciam seu conhecido trabalho intitulado The Internal Organization of Speech Sounds com esta afirmação (p.245):

Nos últimos anos, tornou-se largamente aceito que as unidades básicas da representação fonológica não são segmentos mas traços, os membros de um pequeno conjunto de categorias elementares que se combinam de várias maneiras para formar os sons da fala das línguas humanas.

Em 2009, Clements continua salientando a relevância dos traços na análise fonológica ao sustentar: "Uma descoberta central dos primeiros trabalhos em fonologia foi que os sistemas de sons da fala são estruturados em termos de componentes elementares recorrentes conhecidos como traços" (p.19).

Aceitando-se amplamente a teoria de traços, especialmente por ser capaz de oferecer explicações claras para fenômenos potencialmente não relacionados, destacam ainda Clements e Hume (1995) que os traços facultam explicaçôes para muitas generalizaçôes nos dominios da aquisição da linguagem, dos desvios linguísticos, e da mudança histórica, além de outros.

Com o entendimento da relevância dos traços na busca de respostas para as questôes que suscita o complexo processo de aquisição fonológica, desenvolveramse estudos com essa base teórica, com o suporte de diferentes modelos de traços. No Brasil, muitas pesquisas seguiram essa linha teórica - citam-se aqui alguns 
exemplos: (i) com base em Chomsky e Halle (1968) e Ladefoged (1975): Matzenauer-Hernandorena (1988); (ii) com fundamento em Stevens e Keyser (1989): Matzenauer-Hernandorena (1990); (iii) com os pressupostos da Fonologia Autossegmental: Matzenauer-Hernandorena (1996); Matzenauer (2008); Matzenauer e Miranda (2009); Mota (1996); Rangel (1998, 2002); Duarte (2006), Lazzarotto-Volcão (2009); (iv) com o suporte da Teoria da Otimidade: Matzenauer-Hernandorena e Lamprecht (1997); Bonilha (2000, 2004); Matzenauer e Bonilha (2003); Ferreira-Gonçalves (2008, 2010); Lazzarotto-Volcão (2005); Miranda (2010); Matzenauer (2008, 2012).

Tem de ser destacado que, com o advento da Fonologia Autossegmental, tomados os traços como autossegmentos, a construção do conhecimento fonológico pôde ser vista e explicada de forma inovadora. A nova visão tornouse possível especialmente com o entendimento de que (i) os traços apresentam uma organização ao compor a estrutura interna de um segmento, a qual é formalizada por meio de uma geometria de traços, (ii) traços e segmentos não mantêm relação de bijetividade, já que são autossegmentos, e (iii) os traços podem ir além ou ficar aquém de um segmento.

Assim, diferentemente dos modelos anteriores, a Fonologia Autossegmental permite a interpretação de que, durante o processo de aquisição da linguagem, as crianças constroem gradativamente a estrutura interna dos segmentos, à medida que começam a adquirir os autossegmentos, ou seja, começam a empregar os traços com valor fonológico. De acordo com a proposta de Matzenauer-Hernandorena (1996), o inventário fonológico das crianças parte de coocorrências de traços não marcadas para as diferentes classes de segmentos, prevendo a tendência a que as primeiras consoantes a emergir sejam /p, t, m, n/ $\mathrm{e}$, subsequentemente, à medida que os traços vão sendo incorporados à estrutura interna dos segmentos, o inventário fonológico vai sendo incrementado até a gramática da criança identificar-se com o sistema-alvo.

Tal proposta apresenta dois pressupostos que mostram relevância para uma explicação mais clara acerca do fenômeno da aquisição fonológica: i) a representação fonológica das crianças é diferente da que os falantes adultos têm: a representação vai sendo construída e reconstruída durante o processo de desenvolvimento linguístico; e ii) a constituição do inventário fonológico está na dependência da coocorrência de traços mais do que condicionada pelo comportamento de um traço isoladamente. 
A primeira das pressuposições apresentadas é capaz de oferecer resposta plausível à primeira das questôes levantadas a partir da Teoria da Fonologia Natural, conforme formulada ao final da Seção 3.2: as formas de input, durante o desenvolvimento linguístico, são próprias da criança; a representação fonológica de que ela dispõe não é igual à do adulto, pois depende de sua capacidade de percepção e de construção gradual da gramática.

Plenamente compatível com os pressupostos acima defendidos, relativos à aquisição fonológica, estão dois outros modelos teóricos: um primeiro, de Clements ([2005] 2009), que pode ser denominado Modelo de Princípios Fonológicos Baseados em Traços, e um segundo, de Boersma (2006, 2007, 2008, 2010) e Boersma e Hamann (2009), designado Modelo de Processamento de L1.

Pelo modelo de Clements ([2005] 2009), há princípios que regem a constituição dos inventários fonológicos das línguas, os quais respondem, entre muitas outras questões, por que as línguas não têm apenas plosivas e nasais ou por que alguns traços, e não outros, têm papel contrastivo na maioria dos sistemas linguísticos. À luz desse modelo, aspectos relevantes do processo de aquisição fonológica ganham explicação consistente, como o ordenamento na aquisição de oposições entre segmentos e a relevância das classes naturais no comportamento da fonologia durante o desenvolvimento linguístico. Exemplos de estudos com essa base teórica estão em Matzenauer (2008, 2010, 2011) e Lazzarotto-Volcão (2009).

O modelo de Boersma, que se constitui em um modelo de processamento e em um modelo de gramática, formalizado por meio de restrições em consonância com os pressupostos da Teoria da Otimidade, congrega fonética e fonologia, bem como compreensão / percepção e produção. Prevê a existência de três níveis de representação - um nível fonético e dois fonológicos - que contêm, respectivamente, a forma fonética, a forma fonológica de superficie e a forma subjacente, articuladas por meio de restrições. Com esse pressuposto teórico, a aquisição fonológica pode ser vista como a construção gradual do sistema-alvo, a partir da percepção fonética até a constituição da representação subjacente, permitindo a visualização e a formalização dos movimentos de construção e reconstrução de representações durante o desenvolvimento linguístico, tanto em se tratando do chamado módulo da compreensão como do módulo da produção linguística. São estudos exemplificativos sobre a aquisição da fonologia do PB que têm esse suporte teórico: Matzenauer (2011); Matzenauer e Miranda (2012).

A análise do fenômeno da aquisição, sob o fundamento desses modelos, foi capaz de apresentar avanços importantes, especialmente no entendimento de 
questôes relativas à construção gradativa do conhecimento fonológico pela criança, incluindo, por exemplo, a constituição de representações fonológicas, a formação de classes naturais de segmentos, o ordenamento da disponibilização fonológica de traços e de segmentos, os tipos de processos empregados pelas crianças, além de formalização dos fenômenos que caracterizam o desenvolvimento fonológico. Com o fundamento em traços, a seguir é mostrada uma breve visão dos dados de L, em seu processo de desenvolvimento fonológico.

\subsection{Abordagem dos dados de $L$ com base em traços}

Observados os dados de L, cujos exemplos estão apresentados na Seção 2, considerando-se o traço como unidade de análise, obtêm-se resultados diversos daqueles mostrados na Seção 3.2.

Em uma rápida e simplificada observação, caracteriza-se a Fase 1 como o estágio que contém fundamentalmente duas estruturas de segmentos, que determinam as duas classes fonologicamente estáveis (plosivas e nasais), em razão das coocorrências de traços integrantes da gramática fonológica de L. Nessa fase, há praticamente a ausência da classe das fricativas, tendo esses segmentos o emprego de uma plosiva em seu lugar. Em razão desse fato, ao tratar-se da classe das fricativas, na fase em que apenas a labial desvozeada integra a fonologia da menina, tem-se que ainda não está estabilizada a oposição fonológica determinada pelo traço [+contínuo], em coocorrência com o traço [-soante] (a coocorrência [-soante, -contínuo], que se mostra estável para L, é responsável pelo emprego fonológico da classe das plosivas). Também na classe das fricativas não se mostra estável a coocorrência do traço [-soante] com o traço de ponto [anterior]. Por outro lado, no sistema de L, a oposição determinada pelo traço [ \pm voz], em coocorrência com [-soante], parece estar adquirida, uma vez que seu valor é sempre preservado, mesmo no emprego de outros segmentos em lugar de alvos [ \pm voz].

Essa breve descrição é capaz de apontar que a fonologia de L apresenta apenas algumas coocorrências de traços, do que decorre que somente poucas estruturas internas a segmentos estejam disponíveis e que, então, haja restriçóes no emprego de classes / segmentos fonológicos.

Com uma visão autossegmental de traços, é possível explicitar-se a construção e reconstrução dos segmentos na fonologia da criança, como também é possível formalizar os fenômenos que caracterizam o sistema linguístico. 
A seguir, tem-se um exemplo de estrutura que evidencia o comportamento fonológico de segmentos na gramática de L, formalizada em uma geometria de traços. Na Fase 2 deste estudo (Seção 2), quando L, na classe das fricativas, apenas mostra estabilidade fonológica nas consoantes labiais, empregando fricativas coronais anteriores por menos anteriores e vice-versa, a estrutura de traços que sua fonologia tem representada, para essa classe de consoantes, parece ser formalizada conforme mostra a geometria em (1) - o(s) traço(s) cujo emprego não se mostra estabilizado está ligado à estrutura por meio de linhas pontilhadas.
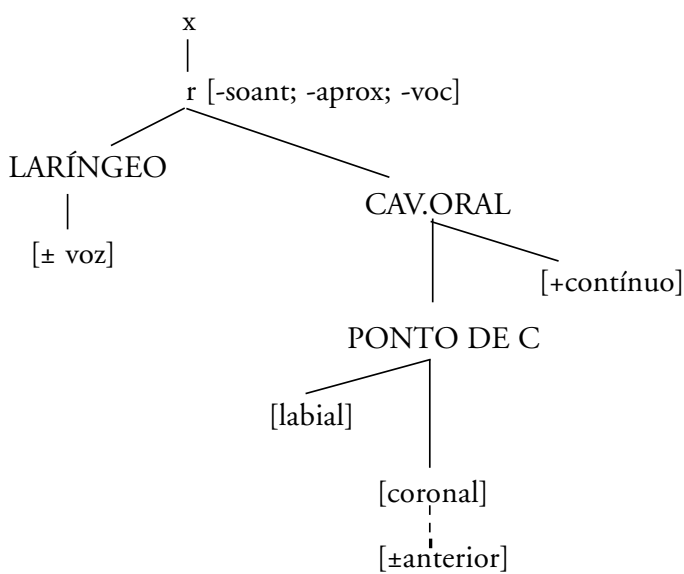

A ocorrência de alternâncias entre as fricativas coronais, presente nos dados de L nas três fases acompanhadas neste estudo (veja-se Seção 2), pode ser explicada pela não estabilização do valor contrastivo do traço [anterior], dependente do traço [coronal], conforme formaliza a representação em (1). Tal fato leva ao entendimento da aquisição precoce dos três grandes traços de ponto - [labial], [coronal] e [dorsal] - em etapa precedente à aquisição do traço de ponto subsidiário [ \pm anterior], ou seja, em razão de somente contrastar os três traços de ponto e por não ainda atribuir valor fonológico ao traço subsidiário [ \pm anterior], a menina emprega tanto o processo de anteriorização como o de posteriorização às fricativas coronais; o fato de o traço [ \pm anterior] poder ser dependente apenas do traço de ponto [coronal] explica por que os processos de anteriorização e de posteriorização têm como alvo primordialmente as fricativas coronais. Em havendo um ordenamento na aquisição dos traços de ponto, sendo o [anterior] o último a se mostrar fonologicamente estável, chega-se à confirmação de que a oposição 
entre /f/ e /s/, por exemplo, é anterior, no processo de aquisição, à oposição entre $/ \mathrm{s} / \mathrm{e} / \mathrm{S} /$.

$\mathrm{Na}$ fase anterior a essa, quando L empregava plosivas em lugar de fricativas, na geometria de traços a formalização deveria mostrar linha pontilhada na vinculação do traço [contínuo]; se fricativas labiais fossem empregadas no lugar de coronais, a linha que associa o traço [coronal] também teria de aparecer pontilhada. Com esses exemplos, é possível evidenciar a clareza com que o modelo pode explicitar e formalizar a construção gradual da estrutura interna dos segmentos, durante o processo de aquisição fonológica.

Com base em seus pressupostos, a Fonologia Autossegmental mostra-se competente, portanto, para explicar e representar formalmente o emprego de um segmento por outro no decurso da aquisição: o uso de plosivas por fricativas pode ser expresso como a não estabilização da coocorrência dos traços [-soante, +cont], além de formalizar tal fenômeno; o não estabelecimento do contraste fonológico [ \pm cont $]$ nesse contexto leva a verificar-se por que a menina emprega o processo de plosivização de fricativas.

Ainda há que se explicar por que, nas Fases 2 e 3 deste estudo, os dados de $\mathrm{L}$ apresentam o emprego do glide coronal em lugar de líquidas. Pela Fonologia Autossegmental, é consistente arguir-se a existência potencial de um nó Vocálico implicado pela coocorrência, na raiz, dos traços [+aproximante, +soante], conforme defende Matzenauer-Hernandorena (1996). A representação é mostrada em (2), com os traços não estáveis e / ou potenciais ligados à geometria por linhas pontilhadas.

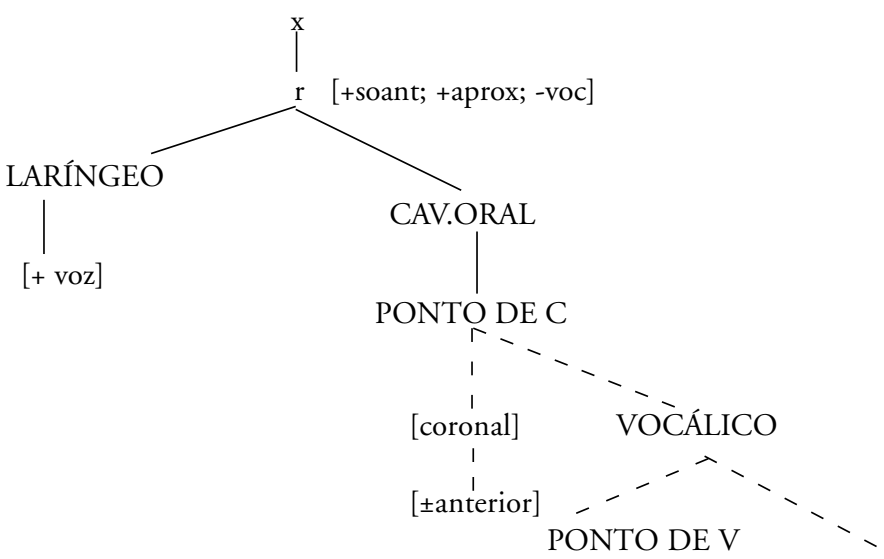

ABERTURA 
Essa estrutura implicacional que se defende estar presente nas consoantes líquidas - que decorre, segundo esse pressuposto, da imanência dos traços maiores - é capaz de evidenciar por que, em etapas do processo de aquisição fonológica, assim como em certos dialetos do $\mathrm{PB}$, há o emprego do processo de semivocalização de líquidas: quando há a semivocalização, vem à superfície o nó Vocálico potencial, deixando de ligar-se, à estrutura interna do segmento, o traço de ponto imediatamente vinculado ao nó Ponto de C, que representa a articulação consonantal.

Com esse encaminhamento, aqui apenas exemplificado com um número muito restrito de fenômenos, a Fonologia Autossegmental parece oferecer dispositivos teóricos e formais para responder às questôes deixadas em aberto por uma visão cujo suporte tenha o segmento como unidade de análise, entre as quais três estão expressas no final da Seção 3.2.

Com base nas generalizaçóes captadas pela breve análise mostrada com base na Fonologia Autossegmental, defende-se que modelos que utilizam traços como unidade de análise podem alcançar maior poder explicativo ao focalizarem tanto o comportamento de segmentos durante o processo de aquisição da linguagem como a construção gradual do inventário de consoantes e de vogais pelas crianças.

Ao tomar-se a posição de que os traços são a unidade pertinente para captar generalizações acerca de segmentos e de classes naturais, durante o processo de desenvolvimento fonológico, também se reconhece a pertinência de modelos com base em restrições na análise de fenômenos da aquisição da linguagem.

A Teoria da Otimidade, em variadas versões, utiliza traços ao representar a gramática das línguas por meio de um ranking de restriçôes. Conforme apontam Matzenauer e Miranda (2010), pode valer-se de traços como atributos de segmentos, a exemplo de Chomsky e Halle, ou como autossegmentos, mas também conta com dispositivo representacional e formal poderoso para a explicitação de fenômenos fonológicos, seja do processo de aquisição da linguagem, do funcionamento sincrônico das línguas ou das mudanças que historicamente os sistemas apresentam. Por ser modelo teórico que integra formalmente a noção da marcação, já que categoriza Restrições de Marcação ao lado de Restrições de Fidelidade, com propriedade representa a emergência precoce, no processo de aquisição da linguagem, de estruturas não marcadas diante de estruturas marcadas. Por seus pressupostos, vê a aquisição da linguagem como a construção gradual da gramática pela recorrente reorganização do ranking 
de restrições até chegar ao sistema-alvo, entendimento que oportunizou a proposição de diferentes algoritmos de aprendizagem, que têm alto poder explicativo com relação ao fenômeno do gradual desenvolvimento linguístico.

Discutidas as unidades segmento e traço no processo de aquisição fonológica, passa-se à análise da silaba na construção da gramática pelas crianças.

\section{A sílaba na aquisição fonológica do PB}

$\mathrm{Na}$ tradição gerativa, a sílaba ganhou estatuto de unidade linguística relevante com o trabalho de Liberman e Prince (1977) sobre o acento, anos após a publicação do The Sound Patterns of English (SPE), de Chomsky e Halle, em 1968. O SPE apresenta uma abordagem da fonologia focada em segmentos e traços distintivos em um modelo que não consegue oferecer, em sua arquitetura, instrumentos para uma análise adequada do acento, que é considerado um traço distintivo.

Os estudos sobre aquisição fonológica, desenvolvidos à luz da Fonologia Natural (STAMPE, 1973), fortemente vinculados à perspectiva gerativa em sua formulação inicial, descrevem os fenômenos referentes à sílaba como efeito de processos universais que redundam, no caso da sílaba, em redução e apagamento. Produçōes infantis como ['peda] para 'pedra' e ['fot $\mathrm{j}$ i] para 'forte', por exemplo, são uma consequência da aplicação de processos de Redução de encontro consonantal e Apagamento de consoante final de sílaba. Também processos como Apagamento de sílaba não acentuada, como em [bi'keta] para 'bicicleta’; ou como Epêntese e Metátese, em [pe'regu] e [pergu] para 'prego', são ferramentas descritivas para abordar as produçóes infantis na tentativa de dar conta das diferenças entre as formas dos adultos e das crianças.

A diferença entre as formas alvo e infantil, em se considerando a estrutura silábica, passou a ser analisada diferentemente, como resultado do mapeamento entre unidades segmentais e constituintes prosódicos, a partir do desenvolvimento das fonologias não lineares, o que oportunizou uma mudança na perspectiva de análise, uma vez que a relação entre os output do adulto e da criança passa a ser interpretada como um processo de construção da estrutura silábica, levando-se em conta seus componentes mínimos. A Teoria da Sílaba, seja o modelo autossegmental (KAHN, 1976), seja o métrico (SELKIRK, 1982), traz a ideia de que se trata de uma unidade linguística com estrutura interna, entre cujos constituintes está estabelecida uma relação hierárquica. 
Tal unidade é descrita por Selkirk (1982) como uma unidade composta por dois constituintes imediatos básicos, o onset $(\mathrm{O})^{9}$ e a rima $\mathrm{R}$, sendo o primeiro não obrigatório e possível de ser ramificado, e o último constituído necessariamente de um pico de soância, o núcleo $\mathrm{N}$, e de uma coda $(\mathrm{C})$, elemento opcional. Uma estrutura do tipo CVC tem, seguindo-se este esquema, uma representação como em (3).

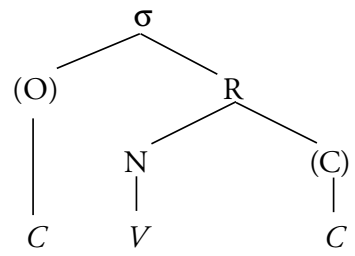

Nas línguas em geral, o preenchimento das posições do esqueleto silábico está sujeito à Escala de Soância, ${ }^{10}$ cujas restriçôes, por ela postas, impedem que consoantes e vogais ocupem uma posição qualquer entre aquelas que, por exemplo, estão representadas em (3). Com base na Escala de Soância, então, é possível terse alguma previsibilidade em relação à formação das diferentes estruturas silábicas observadas nas línguas do mundo, uma vez que o grau de soância ${ }^{11}$ dos segmentos é o que vai definir o preenchimento das posições da estrutura. É possível entender por que os segmentos detentores de maior índice na escala são preferencialmente núcleo da sílaba, as vogais, e por que, nas posiçōes marginais ou mais próximo delas, são encontrados apenas segmentos consonantais cujos índices de soância diminuem gradativamente das líquidas às oclusivas.

O conjunto de estruturas silábicas, representativo dos tipos de estrutura mais frequentes nas línguas do mundo, pode ser derivado de (3), conforme mostra o diagrama em (4):

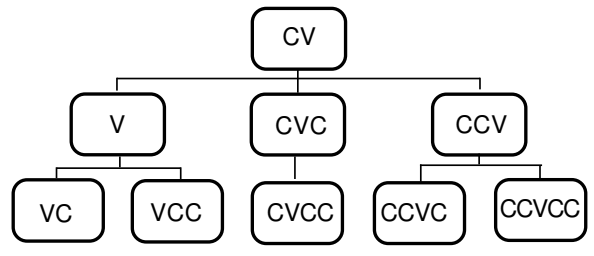

Fonte: MIRANDA, A. R. M.; MATZENAUER, C. L. B. (2010, p. 369) 
Da estrutura silábica básica $\mathrm{CV}$, derivam $\mathrm{V}, \mathrm{CVC}$ e $\mathrm{CCV}$ e, destas, outras mais: VC, VCC, CVCC, CCVC e CCVCC. No português, a sílaba mínima pode ser composta apenas por uma vogal (V) e a sílaba máxima, isto é, aquela com maior número de elementos, por cinco segmentos (CCVCC). As classes de segmentos que podem preencher as posiçóes de $\mathrm{C}$ no esqueleto silábico do português, seguindo a Escala de Soância, obedecem a restriçōes tais como: a segunda posição de onset só pode ser ocupada pelas soantes líquidas /l/ e / / /, como em 'bran.co' e 'blu.sa', por exemplo; a primeira posição da coda, por qualquer soante anterior e pela fricativa coronal /S/, como nas primeiras sílabas das palavras 'por.co', 'cal.ça', 'can.to', 'lei.to', 'cau.da' e 'casca'; e, nos casos em que há o preenchimento da segunda posição de coda, somente é licenciado o / S/, como em 'monstro' e 'pers.pi.caz'(BISOL, 1999).

Estudos sobre a aquisição da fonologia apontam a estrutura CV como aquela que, por ser menos marcada, estará disponível à criança desde suas primeiras palavras, já a ramificação do onset será uma operação verificada mais tardiamente. A ideia de emergência gradual da estrutura silábica e da existência de certa ordem de aquisição é pacífica em estudos sobre a aquisição de línguas, como mostra o quadro em (5), no qual são apresentadas as ordens de aquisição da estrutura silábica referente à ramificação da rima.

\section{Lingua}

Holandês

Catalāo e Espanhol

Português europeu

Português do Brasil
Autor

Fikkert (1994)

Borrás (2008)

Freitas (1997)

Matzenauer-Hernandorena (1990)

\section{Ramificação da Rima}

$\mathrm{CV}>\mathrm{CVC}_{\text {OBsT. }}>\mathrm{CVC}_{\text {SOANTIS }}$

$\mathrm{CV}>\mathrm{CVC}_{\text {NAS }}>\mathrm{CVC}_{\text {LATERA//RRC. }} \mathrm{CVC}_{\text {RÓTICA }}$

$\mathrm{CV}>\mathrm{CVC}_{\text {LLT }}>\mathrm{CVC}_{\text {FRLC. }} \mathrm{CVC}_{\text {ROTICA }}$

$\mathrm{CV}>\mathrm{CVC}_{\mathrm{NAS}}>\mathrm{CVC}_{\text {FRLC. }} \mathrm{CVC}_{\mathrm{ROTTCA}}$

Observa-se, em (5), que a ordem proposta pelos estudos é bastante similar, à exceção do holandês, língua que tem alta frequência de obstruintes em coda. Nos demais, em que línguas romances estão sendo avaliadas, as diferenças estão relacionadas às posições adotadas pelos autores as quais divergem no que diz respeito a aspectos do funcionamento da língua-alvo. Freitas (1997), por exemplo, não considera a nasal como coda do português europeu, pois postula a existência de vogais nasais no sistema; Matzenauer-Hernandorena (1990), por seu turno, não computa as líquidas laterais que, no dialeto falado pelas crianças brasileiras por ela estudadas, é produzida como uma semivogal, resultando, assim, em um ditongo. 
A discussão existente em relação à ramificação da rima apresenta divergências, no caso específico do português, brasileiro e europeu, especificamente, no que diz respeito às nasais e aos glides. Para Bisol (1999), nasais pós-vocálicas e glides ocupam a posição de coda, assim como o fazem as líquidas e a fricativa. Já para Mateus e Andrade (2000), nasais são autossegmentos flutuantes que, embora não ocupem posição esqueletal, funcionam como elementos que fecham a sílaba mesmo sem estar na coda; e glides são unidades derivadas de vogais altas subjacentes não acentuáveis que ocupam a segunda posição de núcleo da sílaba e constituem sílaba aberta. ${ }^{12}$ A defesa de vogais nasais está em Freitas (1997) e Costa e Freitas (2001).

No âmbito da aquisição, uma questão que tem sido abordada nos estudos diz respeito à relação entre a aquisição segmental e a emergência das estruturas silábicas mais complexas. Há indícios de que a estrutura silábica condiciona a produção de segmentos. Nos dados de L, por exemplo, em uma mesma entrevista $(2: 07,29)$, tem-se as palavras [so'vet $\mathrm{i}$ i] (sorvete) e ['gotu] (gosto), em que a fricativa é produzida em onset, mas não em coda medial. Fatos como esse, comuns em dados do desenvolvimento fonológico, revelam uma dificuldade que não está na realização fonética do segmento, mas, sim, na sua emergência associada a determinado constituinte que integra a sílaba.

Em se considerando o tipo de segmento relativo à posição na estrutura silábica, é preciso que se leve em conta o fato de que a emergência segmental, assim como a dos templates silábicos, é gradual. Desse modo, a aquisição de estruturas de sílabas mais complexas pode condicionar a produção de segmentos, como mostra o exemplo da fricativa referido. Há ainda os casos em que a aquisição do segmento ocorre após estarem disponíveis as estruturas silábicas, o que se observa nos dados referentes ao 'r-fraco' que, no português, é o segmento de aquisição mais tardia (cf. MIRANDA, 1996).

Os dados de L sobre a fricativa coronal, apresentados nesta seção, dão suporte a uma reflexão sobre a relação entre a aquisição segmental e a disponibilidade de estruturas silábicas com rima ramificada, bem como à retomada da discussão sobre a rima no português. Em (6), estão apresentados novos exemplos e são retomados alguns daqueles já apresentados na Seção 2, sobre a produção de palavras em que houve contexto para a produção da fricativa, em onset e em coda medial e final. 
(6) Dados de L - produção da fricativa

a) A posição de onset:

\begin{tabular}{|c|c|c|}
\hline ['tusu] & 'urso' & $(1: 09,27)$ \\
\hline ['ôsa] - ['sōsa] & 'onça' & $(1: 10,19)$ \\
\hline ['o $\left.{ }^{\mathrm{n}} \mathrm{sa}\right]$ & 'onça' & $(2: 04,17)$ \\
\hline [so'vet $\left.\int \mathrm{i}\right]$ & 'sorvete' & $(2: 07,29)$ \\
\hline [kân ${ }^{n}$ sada] & 'cansada' & $(2: 11,18)$ \\
\hline
\end{tabular}

b) A posição de coda medial:

\begin{tabular}{|c|c|c|}
\hline ['teta] & 'testa' & $(1: 10,19)$ \\
\hline ['kaka] & 'casca' & $(1: 11,27)$ \\
\hline ['dotu] & 'gosto' & $(2: 02,00)$ \\
\hline [ka’kãw] & 'Cascão' & $(2: 04,17)$ \\
\hline [i’pe $\lambda u]$ & 'espelho' & $(3: 00,04)$ \\
\hline [pe'ka] & [pes'ka]'pescar' & $(3: 01,02)$ \\
\hline$\left[\mathrm{i}^{\mathrm{m}} \mathrm{p}\right.$ esta] & 'impresta' & $(3: 01,02)$ \\
\hline
\end{tabular}

c) A posição de coda final:

\begin{tabular}{|c|c|c|c|c|}
\hline ['majsi] & 'mais' & & & $(1: 07,14)$ \\
\hline ['tusi] & 'avestruz' & & & $(1: 10,19)$ \\
\hline ['zizi] & 'nariz' & ['dojs] & 'dois' & $(1: 11,27)$ \\
\hline ['sejs] & 'seis' & & & $(1: 11,27)$ \\
\hline ['badzi] & 'mais' & ['tuis] & 'avestruz' & $(2: 01,05)$ \\
\hline ['dodzi] & 'arroz' & & & $(2: 02,00)$ \\
\hline ['dozi] & 'dois' & & & $(2: 02,03)$ \\
\hline ['dojs] & 'dois' & & & $(2: 04,17)$ \\
\hline [a'dojs] & 'arroz' & & & $(2: 04,17)$ \\
\hline [a'gos] & 'arroz' & & & $(2: 07,29)$ \\
\hline
\end{tabular}

Desde as primeiras coletas, a fricativa coronal já é produzida em posição de onset, como mostram os dados em (a). A coda medial, porém, somente começou a ser produzida por L aos 3:0, como ilustram os exemplos em (b). A estratégia preponderante foi a omissão e a consequente produção de CV em vez de CVC. Em gravação realizada em abril de 2005, quando L tinha 3:01,02 ocorreu o diálogo entre L e sua mãe, conforme transcrito em (7) e já reportado em Miranda (2009): 
(7) Mãe: o dominó era de letrinhas, filha?

$L^{13}:$ [ $\varepsilon$ de pü'ka] ... [de pe'ka] ... [de pes'ka] ... [de pe:s'ka] ... [de pes'ka:]

O registro em (7) captura um momento de tomada de consciência e de controle da criança sobre sua pronúncia. A mãe não entendeu a primeira produção, de teor inusitado e foneticamente diferente do alvo. A menina, então, percebendo a atitude da mãe, passa a produzir, como se fosse para si, as formas subsequentes. Nesse período, embora a fricativa em coda medial seja ainda instável nas produções de L, pode-se pensar que a estrutura já está disponível à criança. $^{14}$

Quanto à coda final, pode ser observado um comportamento bastante diverso daquele dos dados da coda medial. Em (6c), nos exemplos extraídos do corpus estudado, observa-se a inserção de vogal, resultando em uma estrutura CV.CV em vez de CVC; e a produção precoce do segmento fricativo na posição pós-vocálica a partir da idade de 1:11. A hipótese mais óbvia seria a de que a estrutura CVC já está disponível à criança desde o início de suas produções. Porém, é possível que outra interpretação seja considerada, uma vez que os estudos de aquisição fonológica têm mostrado que a consoante pós-vocálica de final de palavra pode ser produzida em estágios bem iniciais (MIRANDA, 1996; FREITAS, 1997, entre outros). A análise pode, nesse caso, ser guiada pela ideia de que a criança, no início da aquisição, opera com unidades maiores que o traço, o segmento e a sílaba.

De acordo com Macken (1992), a palavra inteira direciona a construção linguística da criança no primeiro período do desenvolvimento. A partir dessas unidades, são formados moldes que levam em conta traços gerais da palavra-alvo. Durante o processo de desenvolvimento, as hipóteses formuladas pelas crianças primeiro ancoram-se na similaridade global entre as palavras, depois em moldes abstratos e, subsequentemente, em moldes que são expandidos e generalizados a novas palavras. Crianças aprendem moldes, segmentos e traços simultaneamente; aos poucos, evidências da palavra como elemento central desaparecem e os dados podem ser adequadamente descritos em termos de segmentos e, posteriormente, de traços. Por essa perspectiva e com base no tipo de dado encontrado nos corpus de $\mathrm{L}$, pode-se interpretar a produção precoce de palavras com [s] final não como a emergência de codas no sistema da criança, mas como resultado de uma operação que envolve uma unidade prosodicamente mais alta que a sílaba, ${ }^{15}$ como representado em (8): 
(8)

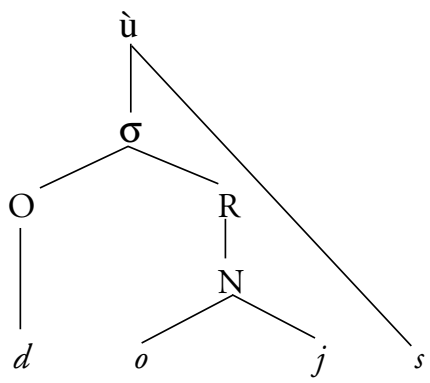

De acordo com (8), a fricativa estaria ligada à palavra prosódica, e não à estrutura silábica. A plausibilidade dessa proposta tem apoio nos estudos sobre a aquisição das codas, os quais têm sido unânimes em assinalar a diferença recém referida entre a produção das codas finais e mediais e também aquela relativa ao tempo de aquisição dos segmentos em posição medial e final. Para MatzenauerHernandorena (1990) e Mezzomo (2004), a diferença etária para a aquisição da coda medial é bastante acentuada. Considerando o tipo de segmento que pode emergir na coda medial, as autoras chegam aos seguintes resultados: nasal > fricativa > rótica; nas faixas etárias de 2:2-2:3, 2:10-2:11 e 4:0-4:1; e nasal, 2:22:4; lateral, 2:6-2:8; fricativa, 3:0-3:2; e rótica 3:8-3:10, MatzenauerHernandorena (1990) e Mezzomo (2004), respectivamente.

Os dados de L ilustram essa evolução, referente ao preenchimento das codas mediais, como mostra (9).

\begin{tabular}{|c|c|c|}
\hline [didaw] & 'dindāo' & $(1: 07,14)$ \\
\hline [di’3ãw] & 'feijão' & $(1: 09,27)$ \\
\hline ['tete] & 'elefante' & $(1: 09,27)$ \\
\hline ['ôsa] ['sõsa] & 'onça' & $(1: 10,19)$ \\
\hline [din'dãw] & 'dindāo' & $(1: 11,00)$ \\
\hline ['tất $\left.\int \mathrm{i}\right]$ & 'elefante' & $(2: 02,00)$ \\
\hline ['kônta] & 'conta' & $(2: 02,00)$ \\
\hline
\end{tabular}

Os ditongos nasais são produzidos por L desde 1:09. Quanto à nasalidade em posição medial, observa-se a primeira produção na faixa de 1:10, ainda como uma propriedade da vogal. Uma vista geral dos dados revela a seguinte sequência de produção nos dados estudados: i) vogais e ditongos orais (1:07), ii) ditongos nasais (1:09), iii) vogais nasalizadas (1:10) e, por fim, iv) o surgimento da consoante nasal pós-vocálica - marca característica do dialeto falado pela criança (1:11). 
Tal sequência foi a mesma observada por Costa e Freitas (2001), autores que defendem a existência de vogais nasais lexicais no sistema do português por julgarem mais econômica essa proposta. Os dados por eles estudados são referentes a dialeto do português europeu que não apresenta a sequência de vogal nasalisada mais consoante nasal nas formas de output, como apresentam os dados de falantes do dialeto de L. ${ }^{16}$

A ordem de aquisição apresentada nos estudos sobre aquisição da fonologia do português é corroborada pelos dados de L (cf. MATZENAUERHERNANDORENA, 1990; RANGEL, 1998; BONILHA, 2004). A diferença em relação ao tempo de aquisição, seja aquela verificada em dados transversais ou nos dados longitudinais apresentados, suscita questôes acerca do estatuto das nasais em posição de coda. Os dados de L mostram um intervalo de, aproximadamente, 12 meses entre a produção da coda medial nasal e da fricativa, uma considerável diferença em relação ao tempo, nesta etapa do desenvolvimento linguístico da criança. Com base nesse significativo intervalo e na ideia de que codas mediais e finais têm estatuto diferente no processo de aquisição, considerase que os resultados indicam que a nasal não é interpretada como uma coda, o que explicaria sua aquisição tão precoce.

A líquida ' $r$ ' e a fricativa, consoantes licenciadas pelo sistema da língua para ocupar a posição de coda, começam a emergir na posição pós-vocálica somente por volta dos três anos, na fala de L. Tal constatação serve como um argumento à postulação de que estas sejam as verdadeiras codas da gramática infantil, como afirma Miranda (2009). Os dados de L mostram que, antes de terem sido produzidas na posição de coda, a fricativa e uma representante da classe das líquidas - o /1/, apontado por Matzenauer-Hernandorena (1990) como a líquida prototípica - já são produzidas em posição de onset, como ilustram os dados ['tusu] e ['ôse] ['sôse], para 'urso' e 'onça', na faixa etária de 1:07-1:10; e [la’fole], para 'lá fora', na faixa dos 2:07.

Duas implicações emergem dessas constatções: a) a aquisição de estruturas silábicas complexas independem, em certa medida, da emergência dos segmentos na gramática da criança, pois, se bastasse o fato de o segmento ser produzido em qualquer posição marginal de uma estrutura como o que foi apresentada em (3), a coda fricativa seria adquirida antes dos dois anos e, subsequentemente, a coda líquida ' $r$ ', ainda que em seu lugar seja produzido um 'l'; e b) a sequência vogal mais consoante nasal, de palavras como 'tampa' e 'tempo', pode estar sendo interpretada pela criança, no início do processo de aquisição da fonologia, como uma vogal com um traço nasal, como defende Freitas (1997), e não como uma estrutura CVC. 


\section{Considerações finais}

Os estudos linguísticos atuais têm efetivamente colocado a aquisição da linguagem como questão central, tanto pela necessidade de desvendar a complexidade de tal fenômeno como pelas evidências que o processo de desenvolvimento linguístico pode oferecer para a proposição de modelos teóricos e para o maior conhecimento sobre a natureza e o funcionamento das línguas. As ideias de Jakobson e de Chomsky, assim como de outros teóricos, continuam sendo revisitadas e reinterpretadas à luz de novas propostas. Extremamente numerosas ainda são as pesquisas cujos resultados reafirmam, na esteira de Jakobson, a existência de padrões na aquisição, bem como confirmam comportamentos paralelos entre aquisição e tipologias de línguas, e entre aquisição e afasia. Também copiosas, com certeza ainda prevalentes, são as investigações que seguem estimuladas pelo Problema Lógico da Aquisição, proposto por Chomsky, perseguindo a hipótese inatista. Os estudos todos desse campo, na atualidade, de modo particular na área da fonologia, assumem a posição de continuidade entre a linguagem da criança e a do adulto, o que lhes permite utilizar modelos teóricos da linguística no embasamento de suas discussões e análises.

Com relação à aquisição da fonologia das línguas, a posição predominante é a da construção gradual do conhecimento fonológico, esteja o foco (a) na ativação de regras fonológicas para relacionar formas subjacentes a formas de superfície, segundo o modelo gerativo clássico, ou (b) na supressão de processos fonológicos naturais e inatos, de acordo com a Fonologia Natural, ou (c) nas representações fonológicas que as crianças constroem, em consonância com os pressupostos dos modelos fonológicos não lineares, ou (d) na hierarquização de restrições, nos moldes da Teoria da Otimidade.

Independentemente da base teórica adotada, o que parece imprescindível aos estudos sobre aquisição fonológica é a atenção às unidades que integram a fonologia das línguas, de modo particular às unidades menores, capazes de captar generalizações responsáveis pelo funcionamento dos sistemas linguísticos: os traços, uma vez que são definidores da constituição de inventários de consoantes e vogais, assim como as silabas, já elas que são o lócus primeiro em que os segmentos (necessariamente resultantes da coocorrência de traços) assumem papel distintivo e decisivo na gramática da língua. E com esses dois tipos de unidades - traços e sílabas - tem-se a relevante relação entre dois níveis da fonologia dos sistemas linguísticos: o melódico e o prosódico. 
Esse entendimento, aliado ao pressuposto de que a construção do conhecimento fonológico implica também a constituição gradual e a possibilidade de reconstituição de formas de representação, encaminha com pertinência para a busca de subsídios, na visão do fenômeno do desenvolvimento linguístico, em modelos teóricos que veem a fonologia com funcionamento não linear: a Fonologia Autossegmental e a Teoria da Sílaba, por exemplo, quando regras forem a base dos modelos; a Teoria da Otimidade, em suas diversas vertentes, quando restriçóes constituírem o seu fundamento. Tais modelos têm mostrado competência para dar respostas a questôes relativas a por que a fonologia da criança difere da do adulto, por que essa diferença mostra sistematicidade e por que o processo de aquisição da fonologia-alvo ocorre de forma gradual.

Embora algumas respostas já tenham sido apresentadas, a partir de investigaçōes realizadas no Brasil ou em cenário acadêmico mais amplo, muitas ainda são as incertezas que interpelam os pesquisadores e muito ainda há a ser feito no campo da aquisição fonológica, de modo particular aliando estudos teóricos e experimentais, visando à garantia do adequado mapeamento entre formas fonológicas e fonéticas, e reunindo produção e percepção, na busca da segurança das afirmaçóes sobre o que pode meramente decorrer de fatores de performance e o que efetivamente reflete o conhecimento fonológico da criança. A aquisição fonológica ainda é uma área de muitas dúvidas e de grandes desafios.

\section{Notas}

${ }^{1}$ Com base em Wasow (1983), Ingram (1989) destaca a oposição entre Language Acquisition e Child Language, duas expressōes que revelam diferentes modos de abordar a aquisição. O primeiro toma como ponto de partida a teoria linguística e volta-se para os dados de aquisição com o intuito de contribuir para questôes relevantes à teoria. $\mathrm{O}$ último caracteriza-se por ser indutivo e as hipóteses emergem de padróes observados no corpus em estudo.

${ }^{2}$ Ingram (1989, p.26) refere duas posições possíveis na perspectiva inatista, o maturacionismo e o construtivismo. Ambas as visões têm a ver com o modo pelo qual a Gramática Universal se torna disponível às crianças. A primeira, na linha de Chomsky, sustenta que os princípios se tornam disponíveis em um tempo geneticamente determinado, enquanto a segunda defende que as mudanças desenvolvimentais ocorrem a partir da construção de estruturas. 
${ }^{3}$ Para Macken (1995, p.672), estão, de um lado, foneticistas e / ou teóricos da aprendizagem (também aqueles filiados à perspectiva Conexionista) e, de outro, fonólogos ou psicólogos cognitivos.

${ }^{4} \mathrm{O}$ presente artigo integra pesquisa apoiada pelo CNPq: Processo no 304138/2007-0 e Processo no 309199/2011-5, e pela FAPERGS: Processo no 11/1294-0.

${ }^{5}$ Não se pode deixar de referir o desenvolvimento de um conjunto significativo de estudos sobre o desenvolvimento considerado atípico (com desvios), dentre os quais são relevantes exemplos: Mota (1996, 2001); Ramos (1996); Keske-Soares (1996, 2001); Lazzarotto-Volcão (2005, 2009); Duarte (2006).

${ }^{6}$ Nos quadros, encontram-se, em um quadrado, os segmentos que ainda não integram a fonologia de L; estão em um círculo os segmentos em processo de aquisição, que ainda mostram alternância ou com outros segmentos ou com um zero fonético.

${ }^{7} \mathrm{O}$ primeiro estudo realizado sobre o processo de aquisição do PB com os fundamentos da Teoria da Fonologia Natural foi a Tese de Teixeira (1985).

${ }^{8}$ Embora os dados não integrem o presente artigo, é relevante salientar que o desenvolvimento linguístico da menina $L$ foi acompanhado até a idade de 5 anos. ${ }^{9}$ No formalismo empregado pós SPE, o parêntese é utilizado para indicar opcionalidade.

${ }^{10}$ A Escala de Soância (Sonority Scale) classifica os sons das línguas de acordo com um parâmetro articulatório. São considerados soantes aqueles sons produzidos com um fluxo de ar relativamente livre e as cordas vocais em tal posição que torne possivel uma sonoridade espontânea (CRYSTAL, 1985, p. 244).

${ }^{11}$ De acordo com Clements (1990, p.12), obstruintes têm menor grau de soância que as consoantes nasais, que, por seu turno, são menos soantes que as líquidas, os glides e as vogais, sendo estas últimas aquelas que ocupam uma posição mais alta na escala, o que as torna, dentre todas, as mais soantes (Escala de soância crescente: plosivas $<$ fricativas $<$ nasais $<$ líquidas $<$ glides $<$ vogais).

${ }^{12}$ Essa posição é também sustentada por Câmara Jr. (1970), Cristófaro-Silva (1999), Lee (1999) e Bonilha (2000).

${ }^{13}$ No dialeto falado por L, os clíticos 'me', 'te', 'se' e 'lhe' são pronunciados sem o alçamento da vogal.

${ }^{14}$ Miranda (1997), ao analisar acusticamente dados de aquisição referentes à rótica em coda medial, encontra indícios de alongamento compensatório da vogal, o que é interpretado pela autora como marca da presença de estrutura CVC no inventário silábico da criança, em momento anterior à emergência do segmento. 
${ }^{15}$ A hierarquia prosódica é composta por constituintes hierarquicamente relacionados: da sílaba, a unidade mais básica, passando pelo pé métrico, a palavra fonológica, o grupo clítico, a frase fonológica e a frase entonacional, até chegar ao enunciado, cada qual ocupando uma posição e desempenhando um papel(cf. NESPOR; VOGEL, 1986). A representação em (6) apresenta apenas os níveis relevantes para o que está sendo discutido, neste caso, a sílaba e a palavra fonológica.

${ }^{16}$ As crianças portuguesas estudadas por Freitas (1997) utilizam estratégia de seleção para evitar a produção de palavras com coda fricativa, mas não a utilizam na produção de palavras que contêm vogais e ditongos nasais, como o fazem na produção das codas fricativas. Esse seria o principal argumento para a postulação de vogais nasais lexicais.

\section{Referências}

BISOL, L. A sílaba e seus constituintes. In: NEVES, M. H. M. (Org.). Gramática do português falado. v.VII. São Paulo: Humanitas/FFLCH/USP; Campinas: Ed. da Unicamp, 1999.

BOERSMA, P. Prototypicality judgments as inverted perception. In: FANSELOW, Gisbert; FÉRY, Caroline; SCHLESEWSKY, Matthias; VOGEL, Ralf (Ed.). Gradience in grammar. Oxford: Oxford University Press, 167-184, 2006.

BOERSMA, P. Cue constraints and their interactions in phonological perception and production. Rutgers Optimality Archive 944, 2007.

BOERSMA, P. Emergent ranking of faithfulness explains markedness and licensing by cue. Rutgers Optimality Archive 954, 2008.

BOERSMA, P.; HAMANN, S. Loanword adaptation as first-language phonological perception. In: CALABRESE, Andrea; WETZELS, W. Leo (Ed.). Loanword phonology, Amsterdam: John Benjamins, 2009. p. 11-58.

BOERSMA, P. Modelling phonological category learning. In: COHN, Abigail C.; FOUGERON, Cécile; HUFFMAN, Marie K. (Ed.). Handbook of Laboratory Phonology. Oxford University Press, 2010.

BONILHA, G.F.G. A aquisição dos ditongos orais decrescentes: uma análise à luz da Teoria da Otimidade. 2000. Dissertação (Mestrado) - Universidade Católica de Pelotas, Pelotas, 2000.

BONILHA G. F. G. Aquisição fonológica do português brasileiro: uma abordagem conexionista da Teoria da Otimidade. 2004. Tese (Doutorado) - PUCRS, Porto Alegre, 2004. 
CÂMARA Jr., J. M. Estrutura da lingua portuguesa. 23. ed. Petrópolis: Vozes, [1970] 1995.

CHOMSKY, N. Aspectos da teoria da sintaxe. 2. ed. Portugal: Coimbra: EditorSucessor, [1965] 1978.

CHOMSKY, N. Sobre natureza e linguagem. São Paulo: Martins Fontes, 2006.

CHOMSKY, N.; HALLE, M. The Sound Pattern of English. New York: Harper and Row, 1968.

CLEMENTS, G. N. The Role of the sonority cycle in core syllabification. In: KINGSTON, J.; BECKMAN, M. E. (Ed.). Papers in laboratory phonology I. Between the grammar and physics of speech. Cambridge: Cambridge University Press, 1990. p. 283-333.

CLEMENTS, G. N. The Role of Features in Phonological Inventories. In: RAIMY, Eric; CAIRNS, Charles E. Contemporary Views on Architecture and Representations in Phonology. Cambridge: MIT Press, 2009.

CLEMENTS, G. N.; HUME, E. V. The internal organization of speech sounds. In: GOLDSMITH, J. (Ed.). Handbook of Phonological Theory. Oxford: Blackwell, 1995. p.245-306.

COSTA, J.; FREITAS, M. J. Sobre a representação das vogais nasais em Português Europeu: evidência dos dados de aquisição. MATZENAUER, C.L.B. (Org.). Aquisição de lingua materna e de língua estrangeira. Pelotas: EDUCAT, 2001. 303p.

CRISTÓFARO-SILVA, T. A interpretação de glides intervocálicos no português. Letras de Hoje, Porto Alegre: v.31, n. p.127-153, 1999.

CRYSTAL, D. Dicionário de linguistica e fonética. Rio de Janeiro: Zahar, 1985.

DONEGAN, P.; STAMPE, D. The study of natural phonology. In: DINNSEN, D. (Ed.). Current approaches to phonological theory, Bloomington: Indiana University Press, 1979. p. 126-173.

DUARTE, S. H. Relaçôes de distância e de complexidade entre traços distintivos na generalização em terapia de desvios fonológicos. 2006. Dissertação (Mestrado) Universidade Católica de Pelotas, Pelotas, 2006.

FERREIRA-GONÇALVES [BONILHA] G. Optimal Geometries in the Acquisition of Portuguese? In: BISOL, L.; BRESCANCINI, C. (Org.). Contemporary Phonology in Brazil. Newcastle: Cambridge Scholars Publishing, 2008.

FERREIRA-GONÇALVES [BONILHA] G. Aquisição. In: BISOL, L.; SCHWINDT, L. C. (Org.). Teoria da Otimidade: Fonologia. Campinas: Pontes, 2010. 
FREITAS, M. J. A aquisição da estrutura silábica do português europeu. 1997. 396p. Tese (Doutorado em Lingüística) - Universidade de Lisboa, Lisboa, 1997.

ILHA, S. E. O desenvolvimento fonológico do português em crianças com idade entre 1:8 a 2:3. 1992. Dissertação (Mestrado) - Universidade Católica do Rio Grande do Sul, Porto Alegre, 1993.

INGRAM, D. First Language Acquisition: method, description and explanation. Cambridge: Cambridge University Press, 1989.

JAKOBSON, R. Child language, aphasia and phonological universals. The Hague: Mouton, 1968.

KAHN, D. Syllable-based Generalizations in English Phonology. 1976. Dissertation. MIT, 1976.

KARMILOFF-SMITH, A. Beyond modularity - a developmental perspective on cognitive science. Cambridge: MIT Press, 1992.

KESKE-SOARES, M.C. Contribuição para um modelo de terapia fonoaudiológica com base na teoria dos traços distintivos para o tratamento de crianças com desvios fonológicos evolutivos. 1996. Dissertação (Mestrado) - PUCRS, Porto Alegre, 1996.

KESKE-SOARES, M. C. Terapia fonoaudiológica fundamentada na hierarquia implicacional dos traços distintivos aplicada em crianças com desvios fonológicos. 2001. Tese (Doutorado) - PUCRS, Porto Alegre, 2001.

KIPARSKY, P.; MENN, L. On the acquisition of phonology. In: MACNAMARA, J. (Ed.). Language learning and thought. New York: Academic Press, 1977. p. 47-78.

LADEFOGED, P. A course in phonetics. Orlando: Harcourt Brace, 1975.

LAMPRECHT, R. R. Os processos nos desvios fonológicos evolutivos - estudo sobre quatro crianças. 1986. Dissertação (Mestrado) - Pontifícia Universidade Católica do Rio Grande do Sul, Porto Alegre, 1986.

LAMPRECHT, R. R. Perfil de aquisição normal da fonologia do português. Descrição longitudinal de 12 crianças: 2:9 a 5:5. 1990. Tese (Doutorado) - Pontifícia Universidade Católica do Rio Grande do Sul, Porto Alegre, 1990.

LAZZAROTTO-VOLCÃO, C. Avaliação e planejamento fonoterapêutico para casos de desvio fonológico com base na Teoria da Otimidade. 2005. Dissertação (Mestrado) - Universidade Católica de Pelotas, Pelotas, 2005.

LAZZAROTTO-VOlCÃO, C. Modelo Padrão de Aquisição de Contrastes: uma Proposta de Avaliação e Classificação dos Desvios Fonológicos. 2009. Tese (Doutorado) - Universidade Católica de Pelotas, Pelotas, 2009. 
LEE, S-H. Sílabas do português brasileiro na visão da Teoria da Otimidade. II Congresso Internacional da ABRALIN. Florianópolis: UFSC, 1999. (ms)

LIBERMAN, M.; PRINCE, A. On stress and linguistic rhythm. Linguistic Inquiry. Cambridge: Mass., v. 8, n. 2, p. 249-336, 1977.

MACKEN, M. Where is phonology? In: FERGUSON, C; MENN, L; STOELGAMMON, C. (Ed.). Phonological development: models, research, implications. The Hague: Holland Academic Graphies, 1992.

MACKEN, M. Phonological acquisition. In: GOLDSMITH, J. (Ed.). Handbook of Phonological Theory. Oxford: Blackwell, 1995.

MATEUS, M. H. M.; d'ANDRADE, E. The phonology of portuguese. Oxford: Oxford University Press, 2000.

MATZENAUER-HERNANDORENA, C. L. Uma proposta de análise de desvios fonológicos através de traços distintivos. 1988. Dissertação (Mestrado) - Universidade Católica do Rio Grande do Sul, Porto Alegre, 1988.

MATZENAUER-HERNANDORENA, C. L. Aquisição da fonologia do Português: estabelecimento de padrôes com base em traços distintivos. 1990. Tese (Doutorado) Universidade Católica do Rio Grande do Sul, Porto Alegre, 1990.

MATZENAUER-HERNANDORENA, C. L. Relações implicacionais na aquisição da fonologia. Letras de Hoje, Porto Alegre, v. 31, n. 2, p. 67-76, jun.1996.

MATZENAUER-HERNANDORENA, C. L.; LAMPRECHT, R. R. A aquisição das consoantes líquidas do português. Letras de Hoje, Porto Alegre, v. 32, n. 4, p. 7- 22, dez. 1997.

MATZENAUER, C. L. B.; BONILHA, G.F. G. Aquisiçãa da Fonologia e Teoria da Otimidade. Pelotas: EDUCAT, 2003.

MATZENAUER, C. L. B. Phonological acquisition and phonological theory: formalizing patterns considering features and segments. In: BISOL, L.; BRESCANCINI, C. (Org.). Contemporary Phonology in Brazil. Newcastle: Cambridge Scholars Publishing, 2008.

MATZENAUER, C.L.B. Gramáticas de sons em desvios fonológicos. In: IX Encontro do CELSUL. Palhoça: UNISUL, 2010.

MATZENAUER, C. L. B. Papéis da teoria fonológica em estudos sobre a aquisição da linguagem. In: VIII ENAL - Encontro Nacional sobre Aquisição da Linguagem/II EIAL - Encontro Internacional sobre Aquisição da Linguagem. Juiz de Fora: UFJF, 2011. 
MATZENAUER, C. L. B. Aquisição das vogais do PB e tipologias de línguas. In: LEE, Seung Hwa (Org.). Vogais além de Belo Horizonte. Belo Horizonte: Faculdade de Letras da UFMG, 2012.

MATZENAUER, C. L. B.; MIRANDA, A. R. M. Traços distintivos e a aquisição das vogais do PB. In: HORA, D. da. Vogais no ponto mais oriental das Américas. João Pessoa: Idéia/UFPB, 2009.

MATZENAUER, C. L. B.; MIRANDA, A. R. M. Variação na aquisição da fonologia. IV Seminário Internacional de Fonologia. Porto Alegre: PUCRS, 2012.

MEZZOMO, C. Aquisição da coda medial no português brasileiro: uma análise via Teoria de Princípios e Parâmetros. 2004. Tese (Doutorado) - Universidade Católica do Rio Grande do Sul, Porto Alegre, 2004.

MIRANDA, A. R. M. A aquisição do 'r': uma contribuição à discussão sobre seu status fonológico. 1996. 125p. Dissertação (Mestrado em Letras) - Universidade Católica do Rio Grande do Sul, Porto Alegre, 1996.

MIRANDA, A. R. M. A assimilação de consoantes na fala infantil: uma abordagem auto-segmental. In: Anais do I Encontro do CELSUL. Florianópolis: UFSC, 1997. MIRANDA, A.R.M. Os dados de aquisição oral e escrita e o estatuto das codas mediais do português. In: FERREIRA-GONÇALVES, G.; KESKE-SOARES, M.; BRUM-DE-PAULA, M. Estudos em Aquisição Fonológica. Santa Maria: Pallotti, 2009. (v. 2)

MIRANDA, A. R. M. A interação entre acento e sílaba na aquisição da linguagem: um exemplo de marcação posicional. Letras de Hoje, v. 45, p. 27-34, 2010.

MIRANDA, A. R. M.; MATZENAUER, C. L. M. Aquisição da fala e da escrita: relações com a fonologia. Cadernos de Educação, Pelotas: UFPEL, v. 35, p. 359-405, 2010.

MOTA, H. B. Aquisição segmental do Português: um modelo implicacional de complexidade de traços. 1996. Tese (Doutorado) - Universidade Católica do Rio Grande do Sul, Porto Alegre, 1996.

MOTA, H. B. Terapia fonoaudiológica para os Desvios Fonológicos. Rio de Janeiro: Revinter, 2001.

NESPOR, M.; VOGEL, I. La prosódia. Madrid: Visor Distribuiciones S.A., [1986] 1994.

RAMOS, A. P. F. Avaliação e tratamento fonológico de crianças portadoras de fissuras do lábio e do palato reparadas na faixa etaria de 4 a 9 anos. 1991 Dissertação (Mestrado) - Universidade Católica do Rio Grande do Sul, Porto Alegre, 1991. 
RAMOS, A.P.F. Processos de estrutura silábica em crianças com desvio fonológico evolutivo: uma abordagem não-linear. 1996. Tese (Doutorado) - PUCRS, Porto Alegre, 1996.

RANGEL, G. A. Uma análise auto-segmental da fonologia normal: estudo longitudinal de três crianças de 1:6 a 3:0. 1998. Dissertação (Mestrado) - Universidade Católica do Rio Grande do Sul, Porto Alegre, 1998.

RANGEL, G. de A. Aquisição do sistema vocálico do Português Brasileiro. 2002. Tese (Doutorado) - PUCRS, 2002.

ROSA, S. F. Desenvolvimento fonológico do português - descrição longitudinal de 6 crianças: 2:8 a 3:2. 1992. Dissertação (Mestrado) - Universidade Católica do Rio Grande do Sul, Porto Alegre, 1992.

SELKIRK, E. The syllable. In: HULST, H.; SMITH, S. (Ed.). The structure of phonological representations. Dordrecht: Foris, 1982. v.2, p. 337-379.

SLOBIN, D. Psicolinguistica. São Paulo: Nacional, 1980.

STAMPE, D. A Dissertation on Natural Phonology. Ph.D. (Dissertation) - Chicago: University of Chicago, 1973.

STEVENS, K. N.; KEYSER, S. J. Primary Features and their Enhancement in Consonants. Language, v. 65, p. 81-106, 1989.

TEIXEIRA, E. R. The acquisition of phonology in cases of phonogical disability in Portuguese-Speaking subjects. 1985. Tese (Doutorado) - PUCRS, Porto Alegre, 1985.

VARELLA, N. K. a aquisição da escrita pelas crianças ocorrem processos fonológicos similares aos da aquisição da fala? 1993. Dissertação (Mestrado) - Universidade Católica do Rio Grande do Sul, Porto Alegre, 1993.

WASOW, T. Some remarks on developmental psycholinguistics. In: OTSU, Y. et al (Ed.). Studies in Generative Grammar and Language Acquisition. Tokyo: International Christian University, 1983.

YAVAS, M. Padrões na aquisição fonológica do Português. Letras de Hoje, v. 23, p. 7-30, 1988. 